\title{
스펙경쟁 사회에서 자기계발 동기와 자기계발 강박이 취업준비생의 심리상태에 미치는 영향*
}

\author{
허 창 구 $^{+}$ \\ 대구가톨릭대학교
}

\begin{abstract}
본 연구는 대학생들의 스펙 쌓기와 관련된 심리상태 및 취업 준비행동의 특성을 살펴봄으로 써 스펙 쌓기 과열현상을 심리학적 측면에서 이해하기 위해 수행되었다. 연구 1 은 스펙추구 라는 사회적 현상을 심리적 현상으로 개념화하기 위해 개인의 '자기계발로 정의하고 이를 측정할 수 있는 자기계발 동기(향상적, 예방적) 척도와 강박적 자기계발 척도를 개발하였다. 개발된 세 가지 자기계발(향상적, 예방적, 강박적) 척도는 양호한 구성타당성을 보여주었으며 조절초점척도(향상, 예방), 학습지향성척도(숙달목표, 수행목표), 걱정 및 강박척도와 논리적으 로 타당한 상관관계를 보여주었다. 연구 2는 세 가지 자기계발이 대학생들의 진로 및 취업 관련 심리변인(취업불안, 진로성숙도, 진로의사결정, 진로준비행동, 내면적 편견, 삶의 만족) 에 미치는 영향을 확인하기 위해 수행되었다. 그 결과 향상적 자기계발의 긍정적인 영향에 대한 가설과 강박적 자기계발의 부정적인 영향에 대한 가설이 모두 지지 되었다. 한편, 부정 적인 영향을 미칠 것으로 가정했던 예방적 자기계발의 부정적인 영향은 관찰되지 않았다. 본 연구에서 개발한 도구와 연구결과는 진로지도 장면에서 과도한 자기계발로 불편을 호소 하는 학생들의 진단과 상담 및 바람직한 자기계발 교육에 활용될 수 있을 것으로 기대한다.
\end{abstract}

주제어 : 스펙, 자기계발 동기, 강박적 자기계발, 조절초점

\footnotetext{
* 이 논문은 2017년 대한민국 교육부와 한국연구재단의 지원을 받아 수행된 연구임 (NRF-2017S1A5A8019687).

† 교신저자 : 허창구, 대구가톨릭대학교 심리학과, willcando@gmail.com
} 


\section{서 론}

1990년대 말 외환위기 이후 2000년대 초 세 계경제위기를 거치면서 가중된 청년취업난으 로 인해, 대학생들은 학업 이외에도 또 다른 경쟁력 즉, ‘스펙 쌓기 경쟁'에 몰입하고 있다. 취업환경의 개선에 대한 희망이 희박해짐에 따라, 취업경쟁에서 낙오자가 되는 데 대한 불안감(Bauman, 2013)으로 대학생들은 기존의 학벌 위주 경쟁력을 넘어서 추가적인 역량 쌓 기에 집중하기 시작했다.

대학생의 $84.6 \%$, 직장인의 $89.0 \%$ 가 평소 자 기계발에 대한 강박감을 느낄 정도로 스펙경 쟁이 과열되면서(Job Korea, 2016. Aug. 22), 결 과적으로 3 대 스펙에 이어 5대 스펙과 8대 스 펙이 등장하는 등 지속하여 스펙의 양과 질이 높아지고 있다(Chae, 2012; Kim, 2012; Oh, 2013). 하지만 구직자의 기대와는 달리 스펙은 구직자의 면접확률에 영향을 미치지 못했으며 (Lee, 2014), 기업 취업 후 성과와도 관련성이 없는 것으로 나타났다(Ban, 2014). 최근 스펙을 탈피한 채용을 표방하는 기업들이 늘어나고 있으나 이미 대학생들 사이에서 보편화 된 스 펙경쟁은 여전히 대학생들에게 시간적, 경제 적, 정신적 부담으로 작용하고 있다(Lee, 2008; Shin \& Moon, 2014).

이러한 스펙경쟁 현상에 대해 그동안의 학 문적 접근방식은 주로 사회학적인 관점을 취 해왔다. 즉, 스펙의 종류에 대한 조사연구 (Kang, 2012), 스펙경쟁의 사회 구조적 문제 (Shin \& Moon, 2014), 스펙이 취업도움이나 업 무수행에 미치는 영향(Ban, 2014; Lee, 2014; Jang, 2013) 등과 같이 스펙경쟁으로 인한 사 회적 부작용을 지적하면서 그 원인을 사회의 구조적 문제에서 찾았다.
스펙경쟁을 사회적인 현상으로만 해석하는 데는 한계가 있다. 스펙경쟁의 중심에서 스펙 에 대한 부담감을 피부로 느끼면서 스펙 쌓기 를 계속해 나가고 있는 당사자는 취업준비생 들이며, 스펙 쌓기로 인한 이익 혹은 피해를 경험하는 당사자도 취업준비생들이다. 따라서 취업준비생들이 스펙추구 행동을 지속하는 이 유를 이해하기 위해서는 이들이 겪고 있는 정 서적 경험, 자신의 상황에 대한 해석, 상황에 대처하는 동기적 반응 등 취업준비생들의 행 동에 영향을 미칠 수 있는 심리적 특성들을 함께 고려할 필요가 있다 하겠다.

현재 스펙추구 행동과 관련하여 개인의 심 리적 상태를 진단하는 도구나 스펙추구 과정 에서 구직자가 겪는 심리적 결과들에 관한 연 구는 찾기 어려운 실정이다. 비록 관련 연구 로 Cho(2008)의 '취업불안' 척도개발 연구가 진 행된 바 있으나 척도의 내용이 결과적인 취업 여부에 국한되어 있어 구직준비 과정에서 경 험하는 심리적 특성을 진단할 수 없으며, 취 업불안을 유발하는 상황, 원인, 상태 등 불안 요인으로만 구성되어 있으므로 불안 이외의 스펙추구 동기를 다양하게 다루지 못한다는 한계가 있다. 이와 관련하여 Lee와 $\operatorname{Kim}(2004)$ 은 대학생들의 심리적 특성(직업탐색 자기효 능감, 특성불안, 외향성)에 따라 취업준비행동 (직업탐색, 구직행동)이 달라지는 결과를 보여 주면서, 개인의 심리적 특성에 따른 고유한 취업준비 전략이나 패턴이 있는지에 관한 연 구가 이루어져야 함을 주장한 바 있다.

따라서 본 연구는 스펙추구 행동에 관한 심 리학적 이해의 폭을 넓히기 위해 다음과 같은 목적으로 연구를 진행하였다. 첫째, 동기이론 을 바탕으로 스펙추구의 동기를 측정할 수 있 는 '자기계발동기 척도'를 개발하는 것이다. 전 
술한 바와 같이 스펙과 관련된 기존 연구들이 스펙경쟁 당사자의 심리적인 특성을 고려하지 못한 이유 중 한 가지는 스펙과 관련된 심리 측정 도구의 부재가 원인일 것이다. 따라서 스펙추구 동기의 측정을 통해 스펙경쟁 현상 에 관한 심리학적 접근의 토대를 마련하고자 한다.

둘째, 과도한 스펙추구 경향을 측정하는 '강 박적 자기계발 척도를 개발하는 것이다. 대학 생들의 자기계발 노력은 역량증진 및 취업준 비를 위해 필요한 과정이지만, 그러한 동기가 과하거나 강박적인 경우에는 지나친 긴장을 유발하여 오히려 자신의 현 상태를 비관적으 로 해석하게 되며, 진로의사결정이나 진로발 달을 저해할 수 있다. 따라서 강박적 자기계 발 척도의 개발을 통해 과도한 스펙경쟁에 대한 심리학적 접근을 시도하고자 한다.

셋째, 자기계발 동기와 강박적 자기계발 경 향이 취업준비생의 심리적 상태에 미치는 영 향을 경험적으로 검증하는 것이다. 취업준비 스트레스는 대학생활적응에 부정적인 영향을 미치고 있으며(Kang, 2012), 취업준비생들은 스 트레스로 인한 우울증, 긴장감 등 정신건강 상의 문제를 경험하고 있다(Lee \& Kang, 2011; Jung \& No, 2001). 자기계발 동기 및 강박적 자기계발은 취업준비생들이 겪는 다양한 심리 적 현상의 원인과 결과를 이해하데 도움을 줄 수 있을 것이며, 이러한 심리학적 접근은 기 존의 사회학적 접근과 함께 스펙추구 행동에 관한 이해의 폭을 넓혀줄 수 있을 것이다.

\section{연구 1}

연구 1 은 자기계발 동기와 강박적 자기계
발 수준을 측정하는 도구를 개발하기 위해 수행되었다. 자기계발 동기는 조절초점이론 (Higgins, 1997)에 근거하여 향상초점과 예방초 점으로 구분하여 문항을 구성하였으며, 강박 적 자기계발은 다양한 강박 관련 구성개념을 참고하여 문항을 구성하였다.

\section{이론적 배경}

\section{스펙과 자기계발}

스펙(spec)은 'specification'의 줄임말로서 사전 적 의미는 기계나 제품 따위가 어떠한 성능 과 기능을 가졌는지를 나타내주는 사양'을 의 미하는 단어였으나, 2000년대 초반 한국사회의 변화를 반영하는 신조어로 표준국어대사전에 '직장을 구하는 사람들 사이에서, 학력 - 학점 - 토익 점수 따위를 합한 것을 이르는 말이 라고 정의되었다(Park, 2004).

본 연구에서 스펙의 용어와 정의를 어떻게 다룰 것인가를 결정하는 데는 몇 가지 고려할 사항이 있다. 첫째, ‘스펙'이라는 용어는 취업 과 관련된 사회적 요구사항으로 해석되므로, 취업준비생의 노력에 대한 심리학적 접근을 위해서는 이들의 심리적 과정을 내포할 수 있 는 용어로 다시 정의할 필요가 있다. 둘째, 스 펙은 사람마다 추구하고 있는 영역과 수준이 상이하며, 시기와 상황 및 가치관에 따라 달 라지는 '비균질적' 용어이므로(Jang, 2013), 취 업준비생들이 추구하고 있는 스펙의 영역과 수준을 동일한 방식으로 해석하기 어려운 점 이 있다.

이러한 이유로 본 연구는 ‘스펙' 개념을 심 리특성으로 개념화하고, 다양한 상황에 일반 
화시킬 수 있도록 '자기계발'로 재정의하고자 한다. 심리학적 관점에서 자기계발은 자아 탐 색과 성장, 혹은 심리적 효용을 가져오는 자 발적인 학습행위 $(K i m$ \& Lee, 2009; Seligman, 2004)이며, 삶의 특정 영역에 관해서 자기의 발전에 필요하다고 생각되는 학습에 투자하는 모든 노력과 활동(Kim \& Kim, 2017)을 의미하 므로 시기, 상황, 개인차와 관계없이 적용할 수 있는 개념으로 볼 수 있다. 또한, 자기계발 도 스펙추구와 마찬가지로 끊임없이 추구되는 측면이 있으며(McGee, 2005), 20대에게 스펙은 자기계발 그 자체 $(\mathrm{Oh}, 2011)$ 로 볼 수 있다는 점에서 스펙을 일반화할 용어로 '자기계발'을 사용하는 것이 적합할 것으로 판단하였다.

\section{조절초점과 자기계발 동기}

대학생의 자기계발 동기와 관련된 기존 연 구들은 대부분 자기계발 동기가 '취업불안과 관련되어있음을 보여주었다. 예를 들어, 사회 불안이 높을수록 더 열심히 취업준비를 해야 한다고 인식하고 있었으며(Iem, 2018), 취업불 안이나 스트레스가 높을수록 실제로 더 많은 취업준비행동을 하는 것으로 나타났다(Jung, 2014; Ko \& Sim, 2014). 하지만 이러한 관점은 대학생들의 자기계발 행동을 설명하는 데 한 계가 있다. 자기계발 동기에는 진로와 취업불 안에 의한 수동적인 동기도 있겠지만, 성장과 학습 옥구에 따른 능동적인 동기도 있을 수 있기 때문이다.

성격 및 사회심리학 모델에서는 이러한 자 기계발 동기의 양면적인 특성을 '바람직한 결 과를 향한 동기'와 '바람직하지 않은 결과를 피하려는 동기'로 구분하고 있다(Bandura, 1986; Carver \& Scheier, 1990; Roseman et al.,
1990). Higgins(1997; 1998)의 조절초점이론 (regulatory focus theory)에 따르면 사람들은 두 가지 지향점을 지니는데, 그중 하나는 이상적 자기지향(ideal self-guide)이고, 다른 하나는 의 무적 자기지향(ought self-guide)이다. 이상적 자 기지향을 하는 사람은 바람직한 상태를 추구 하는 향상초점(promotion focus) 전략을 사용하 며, 의무적 자기지향을 하는 사람은 바람직 하지 않은 상태를 피하는 예방초점(prevention focus) 전략을 사용한다.

요약하면, 능동적으로 자기계발을 하는 사 람은 이상적 자기지향자로서 자기계발의 동기 가 '향상초점적'일 것으로 가정할 수 있으며, 수동적 자기계발을 하는 사람은 의무적 자기 지향자로서 자기계발의 동기가 ‘예방초점적’일 것으로 예상할 수 있다. 따라서 본 연구는 대 학생들의 자기계발 동기의 경향성을 '향상적 자기계발'과 '예방적 자기계발'로 구분하고 각 동기유형의 특성과 영향을 관련 변인과의 관 계를 통해 확인하고자 한다.

\section{강박적 자기계발}

과도한 자기계발을 지칭하는 용어로 '스펙 중독’이라는 표현이 공공연히 사용되고 있다. 하지만, 일반적으로 ‘중독’이란 직접적이면서도 단기적인 쾌감이나 고통완화와 같은 보상경험 에서 비롯되며, 개인적이나 사회적 폐해를 유 발하는 생활의 균형이 깨어진 상태로 정의된 다(Kim, 2002; 2007; Marlatt et al., 1988). 자기 계발 행위의 경우 직접적이고 단기적인 보상 이 없으며, 사회나 타인에게 직접적인 폐해를 유발하지 않고, 때에 따라서는 개인적인 성장 추구라는 긍정적인 목표에 따라 수행된다는 점에서 ‘중독' 개념을 적용하기 부적절한 면이 
있다.

한편, 과도한 행동에 관한 또 다른 개념으 로 '강박행동'이 있다. 강박행동들은 불안감이 나 괴로움을 예방하거나 감소시키려는 목적으 로 수행되지만, 그 수준이 명백히 지나친 경 우를 말하며(Reed, 1985), 부정적 결과의 예방 이나 발생에 대한 책임이 자신에게 있다는 왜 곡된 신념으로 인해 불편감, 불안, 우울 등이 가중되고 이러한 불안을 중화시키는 방안으로 강박행동을 하게 된다(Shin \& Seol, 2007)는 점 에서 과도한 자기계발을 설명하기에 중독보다 적합한 개념으로 볼 수 있다. 따라서 본 연구 는 과도한 자기계발이 취업 및 진로에 관한 불안에서 비롯되었으며, 그 불안을 없애기 위 해 반복적으로 하게 되는 행동이라는 점에서 중독 개념보다는 강박 개념에 가깝다고 판단 하여 '과도한 자기계발'을 '강박적 자기계발'로 개념화하였다.

\section{연구방법}

\section{연구대상}

경상북도에 있는 대학교에서 심리학 및 공 학 과목 수강생 298명을 대상으로 설문조사를 실시하였다. 참여자는 설문 응답에 앞서 조사 자에게 연구목적 및 내용에 관한 설명을 들었 고, 설문에 자발적으로 참여한다는 동의서에 서명하였다. 성별은 남자 $33.2 \%$, 여자 $66.8 \%$ 였 으며, 학년의 분포는 모든 학년에서 비슷한 수준이었다(21.1\% 32.2\%).

연구도구

\section{자기계발 동기 척도}

자기계발에서 모든 행위의 주체는 '자기 (self)'이며, 스스로 변화 필요성을 자각하여 목 표를 설정하고, 계획을 수립하여 실행하고, 그 결과를 검토하게 된다(Jung, 2016). 즉, 자기계 발의 구성개념은 목표설정, 달성과정, 결과해 석이라는 연속된 다차원의 개념으로 이해할 수 있다. 본 연구에서 자기계발의 동기를 구 분하고 해석하기 위해 도입한 조절초점이론에 서도 동기를 향상초점과 예방초점으로 구분하 면서, 이러한 조절초점에 따라 목표, 목표추구 전략, 바라는 결과에서 차이가 나타난다고 설 명하고 있다(Fellner et al., 2007).

이와 같은 다양한 차원으로 조절초점을 측 정하는 척도로는 직업장면에서의 조절초점을 측정하기 위해 개발된 WRFS(Work Regulatory Focus Scale; Neubert et al, 2008)가 있는데, WRFS는 조절초점을 세 가지 차원으로 측정 하고 있다. 첫 번째 당위/이상(ought/ideal) 차 원은 동기의 방향이 당위적인 모습을 향한 것인지 아니면 이상적인 모습을 향한 것인 지로 구분함으로써 동기의 궁극적 목표에 관한 정보를 제공한다. 두 번째 성취/안정 (achievement/security) 차원은 동기의 방식이 성 장 중심 추구인지 아니면 안정 중심 추구인지 를 구분함으로써 목표추구 전략에 관한 정보 를 제공한다. 세 번째 이익/손실(gain/loss) 차원 은 동기가 추구하는 결과가 이익추구에 있는 지 아니면 손실회피에 있는지를 구분한다. 본 연구는 WRFS(Neubert et al., 2008)를 기반으로 자기계발 동기의 세 가지 하위차원(목표, 과정, 결과)의 의미에 맞게 문항을 수정하는 작업을 진행하였으며, 수정된 문항을 Table 1에 제시 하였다. 
Table 1. Items of self-development motivation

\begin{tabular}{|c|c|}
\hline & Items $^{\text {a }}$ \\
\hline \multicolumn{2}{|c|}{ Promotive self-development } \\
\hline $\begin{array}{l}\text { Goal } \\
\text { (ideal) }\end{array}$ & $\begin{array}{l}\text { I give priority to development that will help me with my hope for the future. } \\
\text { I try to reach the ideal I hope for. } \\
\text { I spend a lot of time trying to meet my aspirations. }\end{array}$ \\
\hline $\begin{array}{c}\text { Process } \\
\text { (achievement) }\end{array}$ & $\begin{array}{l}\text { I think it is important to help my own development. } \\
\text { I focus on the part that can grow me. } \\
\text { I consider whether it can be an opportunity to grow me. }\end{array}$ \\
\hline $\begin{array}{l}\text { Result } \\
\text { (gain) }\end{array}$ & $\begin{array}{l}\text { I am boldly challenging to maximize my performance. } \\
\text { I take risks to achieve successful results. } \\
\text { I try if I can get a lot of things even if I am likely to fail. }\end{array}$ \\
\hline
\end{tabular}

Preventive self-development

\begin{tabular}{|c|c|}
\hline $\begin{array}{c}\text { Goal } \\
\text { (ought) }\end{array}$ & $\begin{array}{l}\text { I focus on the deficiencies I need to complement. } \\
\text { It is important to develop the ability I deserve. } \\
\text { I try to meet what others expect of me. }\end{array}$ \\
\hline $\begin{array}{c}\text { Process } \\
\text { (security) }\end{array}$ & $\begin{array}{l}\text { I focus on developing the skills I need for a stable future. } \\
\text { It focuses on the development needed to achieve my desire for a stable future. } \\
\text { I think it's important whether it helps in a stable future. }\end{array}$ \\
\hline $\begin{array}{l}\text { Result } \\
\text { (loss) }\end{array}$ & $\begin{array}{l}\text { I tend to develop what I need to avoid failure in the future. } \\
\text { I focus on not going through failure in the future. } \\
\text { I'm focused on preventing the negative consequences that can happen. }\end{array}$ \\
\hline
\end{tabular}

${ }^{a}$ reflects modified items of Work Regulatory Focus Scale(Neubert et al., 2008) to suit self-development.

\section{강박적 자기계발 척도}

본 연구는 강박행동이 불안과 왜곡된 신념 에 기초한다는 점을 근거로 과도한 자기계발 을 '강박적 자기계발'로 개념화하고, 이를 측정 하기 위해 기존의 강박 관련 척도를 바탕으로 자기계발에 대한 과도한 집착이나 잘못된 신 념을 측정하는 문항을 구성하였다.

먼저, 병리적 증상을 측정하지 않으면서도 강박사고나 행동을 측정한 척도로 여가강박
척도가 있다(Yoon et al., 2013). 여가강박 척도 는 여가활동에 대한 집착과 여가활동을 해야 한다는 고정관념을 하위요인으로 담고 있는데, 강박적 자기계발 또한 자기계발에 대한 과도 한 집착과 끊임없이 자기계발을 해야 한다는 고정관념이 원인이 될 수 있다는 점에서 여가 집착은 자기계발에 대한 집착으로, 여가고정 관념은 자기계발에 대한 비합리적 신념으로 이용할 수 있을 것으로 판단하였다. 
다음으로, 자기계발에 대한 조바심이나 불 안을 반영할 수 있는 문항으로는 한국노동패 널조사(Korea Labor \& Income Panel Study, 2014) 에서 사용한 '일에 대한 금단증상' 문항을 이 용하였다. '일에 대한 금단증상'은 Aziz 등 (2013)이 일중독을 다차원으로 측정하면서 포 함시킨 하위차원으로서 업무를 안 하고 있을 때 죄책감, 조바심, 안절부절못한 느낌이 든다 등의 문항으로 구성되어 있어, 본 연구에서 측정하고자 하는 자기계발에 대한 집착의 정 서적 측면을 반영해 줄 수 있을 것으로 판단 하였다. 이어서 자기계발에 대한 비합리적 신 념의 측정 문항을 보강하기 위해 Turner 등 (2016)의 비합리적 수행신념 척도를 이용하였 다. 이 척도는 '나의 역량이 지속해서 발전하
고 개선되지 않으면 견딜 수 없다와 같이 자 기계발과 관련된 왜곡된 고정관념을 측정할 수 있는 문항을 포함하고 있었다.

이상의 문항검토를 바탕으로 본 연구는 여 가강박 척도의 집착과 일중독 척도의 금단증 상 개념을 이용하여 '자기계발 집착 하위개념 을 구성하고, 여가강박 척도의 고정관념과 비 합리적 수행신념 척도의 문항을 이용하여 '자 기계발 고정관념, 하위개념을 구성하였으며, 각 문항을 자기계발 개념에 맞게 수정하였다. 수정된 문항을 Table 2에 제시하였다.

\section{구성타당성 검증을 위한 척도}

본 연구에서 구성한 '자기계발 동기'와 '강 박적 자기계발의 구성개념 타당성을 확인하기

Table 2. Items of obsessive self-improvement

\begin{tabular}{l}
\hline \multicolumn{1}{c}{ Items } \\
\hline Obsession \\
I sometimes have an obsession to make more self-development efforts than others. \\
I have regretted excessive self-development activities because of my compulsion or \\
impulse. \\
I sometimes get too obsessed with activities related to self-development. \\
\hline I feel guilty when I am not developing myself. \\
I am impatient when I am not developing myself. \\
I feel bored and restless without self-development.
\end{tabular}

\section{Stereotype}

I think the results of self-development activities should be valuable and meaningful.

I think that if I get a chance to develop myself, I must do something.

I think that self-development activities should be able to achieve results.

(stereotype)

Competencies that can help must be improved.

I hate being seen by others as someone who does not develop myself.

If I don't continue to improve my capabilities, I'll fail.

${ }^{a}$ Yoon et al(2013), b Aziz et al(2013), c Turner et al(2016) 
위해서는 우선 향상적 자기계발 동기, 예방적 자기계발 동기, 강박적 자기계발의 문항들이 구성개념에 맞게 구별될 수 있어야 한다. 또 한 관련 변인과의 상관관계에서 자기계발 동 기(향상적, 예방적)는 이론적 기반이 된 조절 초점 척도(향상초점, 예방초점)와 관련성을 보 여주어야 할 것이며, 기존 조절초점에 관한 메타연구 결과(Gorman et al., 2012)와 같이 목 표지향성과의 관계에서도 향상적 자기계발 동 기는 숙달목표지향성과 높은 상관관계를, 예 방적 자기계발 동기는 수행목표지향성 높은 상관관계를 보여주어야 할 것이다. 마찬가지 로, 강박적 자기계발은 불안에 근거하여 강박 적으로 나타난 행동이라는 점에서 강박사고, 강박행동, 불안, 걱정 등과 정적 관련성을 보 여주어야 할 것이다.
이를 위해 본 연구에서는 확인적 요인분석 을 통해 두 가지 자기계발 동기와 강박적 자 기계발의 변별성을 확인하였으며, 다음으로 본 연구에서 구성한 문항들과 성향조절초점척 도(Yang \& Kim, 2008), 목표지향성척도(Button et al., 1996), 걱정척도(Kim \& $\mathrm{Min}, 1988)$, 강박 척도(Wilhelm \& Steketee, 2006)의 상관관계를 살펴보았다.

\section{연구결과}

\section{측정변인의 기술통계}

본 연구에서 측정한 변인에 관한 성별 및 학년(저학년: 1-2학년, 고학년: 3-4학년) 간 평

Table 3. Mean difference test by gender and grade (study 1)

\begin{tabular}{|c|c|c|c|c|c|c|c|c|c|c|}
\hline \multirow[t]{2}{*}{ variable } & \multicolumn{2}{|c|}{$\begin{array}{c}\text { Male } \\
(\mathrm{N}=99)\end{array}$} & \multicolumn{2}{|c|}{$\begin{array}{c}\text { Female } \\
(\mathrm{N}=199)\end{array}$} & \multirow[t]{2}{*}{$t$} & \multicolumn{2}{|c|}{$\begin{array}{l}\text { Lower Grade } \\
\qquad(\mathrm{N}=171)\end{array}$} & \multicolumn{2}{|c|}{$\begin{array}{l}\text { Upper Grade } \\
(\mathrm{N}=127)\end{array}$} & \multirow[t]{2}{*}{$t$} \\
\hline & $M$ & $S D$ & $M$ & $S D$ & & $M$ & $S D$ & $M$ & $S D$ & \\
\hline \multicolumn{11}{|l|}{ Self-development } \\
\hline Promotive & 3.57 & .51 & 3.49 & .50 & 1.18 & 3.55 & .50 & 3.48 & .51 & 1.24 \\
\hline Preventive & 3.61 & .55 & 3.60 & .47 & .06 & 3.58 & .49 & 3.63 & .50 & -.80 \\
\hline Obsessive & 2.91 & .72 & 2.96 & .65 & -.53 & 2.88 & .69 & 3.02 & .66 & -1.71 \\
\hline \multicolumn{11}{|l|}{ Regulatory focus } \\
\hline Promotion & 3.73 & .50 & 3.78 & .43 & -.79 & 3.58 & .52 & 3.54 & .55 & .60 \\
\hline Prevention & 3.26 & .71 & 3.31 & .62 & -.62 & 3.63 & .56 & 3.59 & .52 & .52 \\
\hline \multicolumn{11}{|l|}{ Goal orientation } \\
\hline Learning & 3.73 & .54 & 3.47 & .50 & $4.05 * *$ & 3.15 & .57 & 3.12 & .59 & .42 \\
\hline Performance & 3.49 & .58 & 3.67 & .52 & $-2.70 * *$ & 3.08 & .49 & 3.09 & .54 & -.32 \\
\hline Worry & 3.02 & .52 & 3.12 & .50 & -1.60 & 3.02 & .52 & 3.12 & .50 & -1.60 \\
\hline Obsession & 3.16 & .61 & 3.12 & .57 & .44 & 3.16 & .61 & 3.12 & .57 & .44 \\
\hline
\end{tabular}


균차이 t-test 결과는 Table 3 과 같다. 먼저 학 년에 따른 주요 변인들의 평균 차이를 확인 한 결과, 고학년이 저학년 보다 예방적 자기 계발 및 강박적 자기계발이 다소 높고 향상 적 자기계발은 낮은 경향이 있었으나 통계적 으로 유의한 차이를 보여주지 않았다. 그 밖 에 목표지향성(수행목표, 숙달목표), 걱정, 강 박에서도 통계적으로 유의한 차이를 보여주 지 않았다.

성별에 따른 주요 변인들의 평균차이를 확 인한 결과에서는 남성이 여성에 비해 숙달 목표지향성이 높고 $(t=4.05, p<.001)$, 수행목 표지향성이 낮은 것으로 나타났으며 $(t=-2.70, p<.01)$, 그 밖에 조절초점(접근동기, 회피동기), 자기계발 동기, 강박적 자기계발, 걱정, 강박에서는 성차가 나타나지 않았다.

\section{내적 구성타당성}

본 연구에서 구성한 향상적 자기계발(9문 항), 예방적 자기계발(9문항) 그리고 강박적 자 기계발(12문항)의 구성타당성을 확인하기 위해 $\operatorname{AMOS} 22.0$ 을 이용하여 확인적 요인분석을 실 시하였다. 최적 모형을 찾기 위해 구성개념별 로 측정모형을 구성한 3 요인 모형과 두 자기 계발 동기(향상적, 예방적) 문항과 강박적 자
기계발 문항을 구분한 2 요인 모형, 그리고 모든 문항의 구성개념을 구분하지 않은 1 요 인 모형의 확인적 요인분석 결과를 비교했다. 그 결과 Table 4 와 같이 1 요인 및 2 요인 모 형보다 3 요인 모형의 적합도 지수가 양호했 으며 $C F I=.942 \quad T L I=.904 \quad S R M R=.050$ 로 수용 가능한 수준으로 나타나 예방적, 향상적, 강박 적 자기계발 문항들이 각자 고유의 구성개념 을 측정하고 있는 것으로 확인되었다.

각 구성개념에 속한 문항들의 수렴타당도를 검증하기 위해 평균분산추출 $(A V E)$ 과 개념신뢰 도 $(C R)$ 를 확인한 결과, Table 5 와 같이 예방적 자기계발 $(A V E=.58, C R=.81)$, 향상적 자기계발 $(A V E=.58, C R=.80)$, 강박적 자기계발 $(A V E=.76$, $C R=.85)$ 의 문항들이 모두 해당 구성개념에 양 호하게 수렴하고 있었다. 구성개념 간 변별타 당도를 확인하기 위해 각 구성개념 간 상관관 계를 확인한 결과에서는 상관관계의 범위가 다중공선성을 우려할 수준으로 나타나지 않아 $(r=.14 \sim .42)$, 각 구성개념이 변별적으로 측정 되었음을 보여주었으며, 각 구성개념에 속한 문항들이 보여준 내적합치도(chrobach's $\alpha$ )에 있어서도 향상적 자기계발 .81 , 예방적 자기계 발 .76 , 강박적 자기계발 .86 로 양호한 수준이 었다.

Table 4. The fit of the one, two, and three factor model of self-development sub scale (Study 1)

\begin{tabular}{cccccc}
\hline Model & $\chi^{2}$ & $d f$ & CFI & TLI & SRMR \\
\hline 1 factor (Pro\&Pre\&Obse) & 204.87 & 20 & .643 & .500 & .108 \\
2 factor (Pro\&Pre, Obse) & 117.82 & 19 & .809 & .719 & .084 \\
3 factor (Pro, Pre, Obse) & 47.16 & 17 & .942 & .904 & .050 \\
\hline
\end{tabular}

Note. Pro $=$ Promotive, Pre $=$ Preventive, Obse $=$ Obsessive 
한국심리학회지: 산업 및 조직

Table 5. Convergent and discriminant validity of self-development sub scale (Study 1)

\begin{tabular}{cccccc}
\hline \multirow{2}{*}{ Self-development } & \multirow{2}{*}{ AVE } & C.R & \multicolumn{3}{c}{ Correlation } \\
\cline { 4 - 6 } & & & Promotive & Preventive & Obsessive \\
\hline Promotive & .58 & .80 & $(.81)$ & & \\
Preventive & .58 & .81 & $.30^{* *}$ & $(.76)$ & \\
Obsessive & .76 & .85 & $.14^{*}$ & $.42^{* *}$ & $(.86)$ \\
\hline
\end{tabular}

${ }^{*} p<.05,{ }^{* *} p<.01$, (cronbach's $\alpha$ )

\section{외적 구성타당성}

본 연구에서 구성한 자기계발 동기와 강박 적 자기계발 문항이 관련 변인과의 관계에서 수렴 및 변별 타당성이 나타나는지 확인하기 위해 변인 간의 상관계수를 확인한 결과는 Table 6과 같다. 관련 변인들의 신뢰도는 향상 초점 8문항(.78), 예방초점 8 문항(.79), 수행목표 지향성 8 문항.(77), 숙달목표지향성 8 문항(.80), 걱정 16 문항(. .77$)$, 강박 13 문항(.87) 모두 양호 한 것으로 나타났다.

조절초점 척도의 향상초점은 예방적 자기계 발 $(r=.37, p<.01)$ 보다 향상적 자기계발 $(r=.54$, $p<.01)$ 과 더 높은 정적상관을 보여주었으며,
예방초점은 예방적 자기계발 $(r=.37, p<.01)$ 과 정적상관을 보여주었지만, 향상적 자기계발 $(r=-.02, n . s)$ 과는 관련성을 보여주지 않았다.

목표지향성의 숙달목표지향은 예방적 자기 계발 $(r=.16, p<.01)$ 보다 향상적 자기계발 $(r=.64$, $p<.01)$ 과 더 높은 정적상관을 보여주었으며, 수행목표지향은 향상적 자기계발 $(r=-.08, n . s)$ 보 다 예방적 자기계발 $(r=.38, p<.01)$ 과 더 높은 정적상관을 보여주었다.

걱정척도는 자기계발 강박 $(r=.46, p<.01)$ 및 예방적 자기계발 $(r=.28, p<.01)$ 과 정적 상관관 계를 보여주었으나, 향상적 자기계발과는 아 무런 관련성을 보이지 않았다. 강박척도도 마 찬가지로 자기계발 강박 $(r=.49, p<.01)$ 및 예

Table 6. The correlation between self-developments and related variables (Study 1)

\begin{tabular}{cccc}
\hline \multirow{2}{*}{ Related variables } & \multicolumn{3}{c}{ Self-development } \\
\cline { 2 - 4 } & Promotive & Preventive & Obsessive \\
\hline Promotion focus & $.54^{* *}$ & $.37^{* *}$ & $.28^{* *}$ \\
Prevention focus & -.02 & $.37^{* *}$ & $.50^{* *}$ \\
Learning goal orientation & $.64^{* *}$ & $.16^{* *}$ & .06 \\
Performance goal orientation & -.08 & $.38^{* *}$ & $.42^{* *}$ \\
Worry & -.08 & $.28^{* *}$ & $.46^{* *}$ \\
Obsession & -.07 & $.29^{* *}$ & $.49^{* *}$ \\
\hline
\end{tabular}

$* * p<.01$ 
방적 자기계발 $(r=.29, p<.01)$ 과 정적 관련성을 보여주었으나 향상적 자기계발과는 관련성을 보여주지 않았다.

\section{연구 1 결론}

이상의 결과를 통해 보았을 때, 본 연구의 세 가지 자기계발 문항들은 신뢰롭게 구성되 어 있으며 각각 차별적인 구성개념을 측정하 고 있음을 확인할 수 있었다. 구체적으로 예 방적 자기계발 동기는 기존의 예방초점 및 수 행목표지향성과 정적 관련성을 보여주었으며 걱정이나 강박과도 정적 상관관계를 보여준 데 반해, 향상적 자기계발은 기존의 향상초점 및 숙달목표지향성과 정적 관련성을 보여주었 지만, 걱정이나 강박과는 관련성을 보여주지 않았다. 또한, 강박적 자기계발의 경우 걱정 및 강박과 높은 정적 상관관계를 보여주는 데 반해, 향상적 자기계발과는 관련성을 보여주 지 않았다는 점에서 본 연구에서 구성한 향상 적 자기계발, 예방적 자기계발, 강박적 자기계 발 문항의 내용이 각자의 구성개념을 적절히 반영하고 있다고 판단할 수 있었다.

\section{연구 2}

대학생들이 지닌 자기계발 동기 및 강박적 자기계발 경향성은 이들의 자기계발 행동을 이끌게 될 것이며, 그 과정에서 자기계발 동 기의 유형이나 강박수준에 따라 상이한 심리 적 상태를 경험하게 될 수 있다. 연구 2 는 세 가지 자기계발(향상적, 예방적, 강박적)이 대학 생들의 취업 및 진로 관련 심리적 변인에 미
치는 영향을 확인하기 위해 수행되었다. 이를 위해, 진로 및 취업과 관련된 다양한 영역 즉, 정서영역(취업불안), 의사결정영역(진로미결정), 행동영역(진로준비행동), 태도영역(진로성숙도) 및 전반적 삶의 만족을 측정하였으며, 자기계 발로 인한 사회적인 영향으로 $\mathrm{Oh}(2011)$ 의 연 구에서 제기된 '사회적 차별에 대한 내면적 편견'을 측정하는 문항을 구성하였다.

\section{이론적 배경 및 가설}

\section{자기계발과 취업불안}

불안이란 부정적인 결과가 수반될 수 있는 상황에서 인간이 흔히 경험하는 불쾌하고 고 통스러운 감정이나 정서적 반응을 의미하며, 특히 취업불안이란 취업을 앞둔 사람들이 취 업준비 과정에서 느끼는 불안이다(Cho, 2008).

예방적 자기계발을 하는 개인은 실패로 인 해 발생하는 위험을 경계하고 부모나 주변인 들의 기대를 의식하는 경향이 있으며, 취업을 준비하는 과정에서 취업에 실패할지도 모른다 는 걱정과 취업에 실패할 경우 겪게 될 심리 적 압박에 대한 두려움으로 인해 높은 취업불 안을 경험할 수 있다. 또한, 강박적 자기계발 을 하는 개인의 경우에도 자기계발 노력이 불 안에 근거한 집착이나 잘못된 고정관념에 의 한 것이므로 취업불안이 높을 것으로 예상할 수 있다.

가설 1-1. 향상적 자기계발은 취업불안에 부 적 영향을 미칠 것이다.

가설 1-2. 예방적 자기계발과 강박적 자기계 발은 취업불안에 정적 영향을 미칠 것이다. 


\section{자기계발과 진로성숙도}

진로성숙도는 한 개인이 자신과 직업 세계 에 관한 이해를 바탕으로 자신의 진로를 선택 하고 계획할 수 있는 태도와 능력 발달 정도 이다(Jang, 1991; Kim et al., 2006; Super, 1953).

향상적 자기계발을 하는 개인의 경우 자신 이 얻게 될 긍정적인 성취에 집중하여 도전적 인 목표를 추구하므로, 그 과정에서 자신의 강점 및 적성과 소질을 발견함으로써 진로발 달과업을 성취하고 진로성숙도를 향상시킬 수 있다(Yun \& Kang, 2013). 한편, 취업스트레스와 취업불안이 높을수록 진로성숙도가 낮다는 연 구결과(So \& Park, 2016; Jo, 2010)에 근거하여, 실패에 관한 불안이 내포된 예방적 자기계발 이 향상적 자기계발에 비해 낮은 진로성숙도 를 보여줄 것이며, 특히 강박적 자기계발은 자기계발에 관련한 과도한 집착과 비합리적 신념으로 인해 낮은 진로성숙도를 보여줄 것 으로 기대할 수 있다.

가설 2-1. 향상적 자기계발은 진로성숙도에 정적 영향을 미칠 것이다.

가설 2-2. 예방적 자기계발과 강박적 자기계 발은 진로성숙도에 부적 영향을 미칠 것이다.

\section{자기계발과 진로결정수준}

진로결정수준이란 대학졸업 이후에 일과 관 련한 자신의 진로결정과 확신 정도를 의미한 다(Kim \& Kim, 1997).

향상적 자기계발의 경우 자신이 지향하고 있는 이상 및 포부가 있으며, 타인의 기대에 부응하기보다 자신의 의지에 따른 자기계발을 진행하므로 진로결정수준이 높을 것으로 예상
할 수 있다. 반면, 실패를 회피하는 데 초점을 두는 예방적 자기계발의 경우 실패불안이 높 을 수 있는데, 불안이 높을 경우 동일한 상황 에서도 더 많은 위협을 경험하므로 진로결정 을 회피할 수 있다(Fuqua et al., 1988; Lee et al., 2013). 강박적 자기계발 또한 구체적 자기 계발 목표가 없이 정서적 혹은 비합리적 신념 에 근거한 방향성 없는 자기계발이므로 진로 결정 수준이 낮을 것으로 예상할 수 있다.

가설 3-1. 향상적 자기계발은 진로결정수준 에 정적 영향을 미칠 것이다.

가설 3-2. 예방적 자기계발과 강박적 자기계 발은 진로결정에 부적 영향을 미칠 것이다.

\section{자기계발과 진로준비행동}

진로준비행동은 진로목표의 설정 및 자신이 설정한 진로목표를 달성하기 위해서 개인이 행하는 다양한 준비활동을 의미한다(Kim \& Kim, 1997).

향상적 자기계발을 하는 개인은 이상과 달 성할 수 있는 긍정적 결과에 초점을 둠으로써 진취적이고 도전적인 자세로 목표에 접근하여 진로탐색행동을 증가시킬 것으로 예상할 수 있다(Jo \& Oh, 2001). 한편, 예방초점에 기반 한 예방적 자기계발이나 강박적 자기계발의 경우 실패나 위험과 같이 원하지 않는 상태를 회피하거나 불안을 줄이는 데 초점을 둠으로 써 직업탐색 활동이 활발히 이뤄지지 않을 수 있다(Jo \& Oh, 2001; Kim et al., 1997).

가설 4-1. 향상적 자기계발은 진로준비행동 에 정적 영향을 미칠 것이다.

가설 4-2. 예방적 자기계발과 강박적 자기 
계발은 진로준비행동에 부적 영향을 미칠 것 이다.

\section{자기계발과 사회적 차별에 대한 내면적 편견}

자기계발 경쟁을 사회학적 관점에서 깊이 있게 고찰한 $\mathrm{Oh}(2011)$ 는 자기계발 경쟁의 부 작용으로 타인 고통에 대한 둔감화 및 편견의 확대 재생산과 같은 부정적인 영향을 지적하 고 이를 사회적 차별에 대한 '내면적 편견'이 라 칭했다. 그의 연구에서 대학생들은 비정규 직의 정규직 요구나 파업을 통한 권리쟁취 등 을 경쟁을 통하지 않은 무임승차로 규정하며, 경쟁사회에서의 차별을 당연한 것으로 여기는 모습을 보여주었다.

강박적 자기계발의 경우 미래에 취업과정 에서 발생할 수 있는 부정적 결과에 관한 불 안으로 인해 과도하게 경쟁적으로 자기계발 에 몰입한다. 따라서 타인의 고통에 공감하고 지지하는 것이 향후 자신의 취업과정에서 불 이익으로 작용할 수 있다고 판단되는 경우에 는 자신의 불이익을 감소시키기 위해 타인의 고통에 둔감하게 반응하거나 냉담하게 반응 하는 것과 같이 내면적 편견을 보일 수 있을 것이다.

가설 5. 강박적 자기계발은 내면적 편견에 정적인 영향을 미칠 것이다.

\section{자기계발과 삶의 만족도}

삶의 만족도는 본인이 생각하는 삶의 질에 관한 주관적인 평가로 자신의 삶에 얼마나 만 족하고 있는가를 주관적으로 평가하는 것이다 (Lim, 2012).
진로에 대한 확신, 진로결정 자기효능감이 삶의 만족도에 긍정적인 영향을 미친다는 많 은 연구들(예, Kim et al., 2011; Shin et al. 2015)에 따라, 진로에 대한 확신과 결정감이 높을 것으로 예상되는 향상적 자기계발이 예 방적 자기계발에 비해 높은 삶의 만족도를 보 여줄 것으로 기대할 수 있다.

한편, 취업불안이나 특성불안이 지나치게 높은 경우에는 오히려 취업준비를 포기하거 나 신체적, 정신적 건강에 부정적 영향(Jung, 2014; Lee \& Kim, 2004; Oh, 2014)을 미치며, 대학생들의 인턴, 외부봉사, 학회활동, 홍보대 사 등 많은 대외활동이 오히려 주관적 행복감 을 감소시킨다는 연구결과(Kim et al., 2017)는 불안에 근거한 강박적 자기계발이 대학생들의 삶의 만족도에 부정적인 영향을 미칠 수 있음 을 시사한다.

가설 6-1. 향상적 자기계발은 삶의 만족도에 정적 영향을 미칠 것이다.

가설 6-2. 강박적 자기계발은 삶의 만족도에 부적 영향을 미칠 것이다.

\section{연구방법}

\section{연구대상}

연구대상의 성별, 학년, 전공계열이 고르게 분포되도록, 경상북도 소재 대학교 학생 170 명을 대상으로 오프라인 설문데이터를 수집했 으며 온라인 조사업체를 통해 전국 대학생을 대상으로 113 명의 데이터를 수집하여 총 283 명의 데이터를 분석에 사용하였다. 설문참여 자의 성별은 남자 $55.8 \%$, 여자 $44.2 \%$ 였으며, 
학년의 분포는 1 학년 $25.4 \%, 2$ 학년 $25.1 \%, 3$ 학 년 $23.7 \%$, 4 학년 이상 $25.8 \%$ 였다. 전공계열 분 포는 인문·사회계열 $48.8 \%$, 자연·이공계열 $51.2 \%$ 였다.

\section{연구도구}

자기계발 척도. 연구 1 에서 사용한 향상적 자기계발, 예방적 자기계발, 강박적 자기계발 문항을 이용하였다. 세 가지 자기계발의 신뢰 도는 향상적 자기계발 .82 , 예방적 자기계발 .78 , 강박적 자기계발 .90 으로 양호한 수준이 었다.

\section{취업불안 척도}

Crites(1978)가 개발한 진로성숙도 검사(career maturity inventory)를 바탕으로 Park(2013)이 한 국적 상황에 맞게 수정한 척도를 사용하였다. 5 개 하위차원(진로확정도, 진로독립도, 진로타 협도, 직업선택태도, 진로관여도)이며 총 30 문 항으로 구성되어 있다. $\operatorname{Park}(2013)$ 의 연구에서 진로성숙도의 신뢰도는 .84였으며, 본 연구에 서는 .85 였다.

\section{진로결정수준 척도}

Osipow(1980)에 의해서 개발된 진로결정검사 (career decision scale)를 고향자(1993)가 우리 현 실에 맞게 번안하고 $\operatorname{Kim}$ 과 $\operatorname{Kim}(1997)$ 이 대학 생들의 진로결정수준을 측정하기 위해 수정 보완한 척도를 이용하였다. 하위차원은 진로 확신수준 2 문항과 진로미결정수준 16 문항으로 구성되어 있는데, 본 연구에서는 진로미결정 수준 문항을 역산하여 이용하였다. Kim과 $\operatorname{Kim}(1997)$ 의 연구에서 신뢰도는 .86이었으며 본 연구에서는 .92였다.

\section{진로준비행동 척도}

$\operatorname{Kim}(1997)$ 이 개발하고 Lee(2003)가 두 문항을 새롭게 추가한 진로준비행동 검사를 사용하였 다. 총 18 문항으로 구성되어 있으며, Lee(2003) 의 연구에서 신뢰도는 .88 이었으며 본 연구에 서는 .87 이었다.

\section{사회적 차별에 대한 내면적 편견}

본 연구는 취업과 관련된 내면적 편견을 측 정하기 위해 $\mathrm{Oh}(2011)$ 의 연구에서 '비정규직의 정규직 전환과 관련한 대학생 인터뷰 내용을 이용하여, 동병상련의 대상일 수도 있는 비정 규직 종사자의 요구에 대한 공감수준을 묻는 4 개 문항을 만들었다. 문항의 보기와 내용은 다음과 같다. " $\bigcirc \bigcirc$ 공사에 근무하는 비정규직 노동자들이 정규직 전환을 요구하는 파업을 진행하고 있습니다. 이에 대한 다음의 의견에 대해 당신이 동의하는 정도를 표시해 주세요. 1) 노동자 개인이 최초에 계약직인 것을 알고 입사를 했다면, 이후에 정규직 전환을 요구하 는 건 공정하지 못한 것이다. 2) 비정규직의 정규직 전환 요구는 투쟁으로 정규직이 되겠 다는 비윤리적인 요구이다. 3) 비정규직의 정 규직 전환은 취업을 위해 고생하는 취업준비 생들의 노동기회를 박탈하는 처사이다. 4) 비 정규직이 정규직이 되고자 한다면, 다시 정규 직 시험을 통해 공정하게 경쟁해야 한다." 문 항은 5점 척도로 측정했으며, 점수가 높을수 록 타인의 고통에 대해 둔감하고 내면적 편견 을 지니고 있음을 의미한다. 본 연구에서 사 용한 내면적 편견 4 개 문항의 신뢰도는 .83 이 었다.

\section{삶의 만족도 척도}

Yang(1994)이 개발하고 $\operatorname{Han}(1997)$ 가 수정보 
완 한 생활만족도 척도를 이용하였다. 원척도 는 9개 영역(의식주, 친구관계, 가족 및 친척 관계, 신체 및 정신건강, 직업, 경제, 사회생활 및 여가, 행복감, 자율성 및 자아감)의 만족도 를 측정하고 있으나, 본 연구는 연구대상 및 연구목적에 맞는 사회생활 및 여가(4문항), 행 복감(3문항), 자율성-자아감(3문항)을 이용하 였다. 신뢰도는 $\operatorname{Han}(1997)$ 의 연구에서 .83 이었 으며 본 연구에서는 .92였다.

\section{연구결과}

\section{내적 구성타당성}

본 연구에서 구성한 세 가지 자기계발 척도 의 구성타당성을 연구 1 과 동일한 방법으로 재검증하였다. 확인적 요인분석 결과 Table 7
과 같이 각 하위차원을 독립적인 잠재변인으 로 놓은 3요인 모형의 적합도가 가장 우수한 것으로 나타났다. 또한, Table 8과 같이 각 하 위차원을 구성하는 문항들의 수렴타당성을 보 여주는 평균분산추출 $(A V E)$ 값과 개념신뢰도 (C.R) 값에서도 양호하게 수렴하는 것으로 나 타났으며, 하위차원 간 상관관계도 .39 .54 수 준으로 각 하위차원이 변별적으로 측정되었음 을 보여주었다.

성별, 학년별, 전공별 주요 변인 기술통계치 비교

인구통계학적 변인에 대한 주요 변인들의 평균 차이를 살펴본 결과는 Table 9와 같다. 먼저 성별 비교에서 남학생이 여학생보다 강 박적 자기계발이 높은 것으로 나타났으며 $(t=2.87, p<.01)$, 향상적 자기개발 및 예방적

Table 7. CFA for three models of self-development sub scale (Study 2)

\begin{tabular}{cccccc}
\hline Model & $X^{2}$ & $d f$ & CFI & TLI & SRMR \\
\hline 1 factor (Pro\&Pre\&Obse) & 195.17 & 20 & .778 & .690 & .087 \\
2 factor (Pro\&Pre, Obse) & 169.78 & 19 & .809 & .719 & .079 \\
3 factor (Pro, Pre, Obse) & 54.912 & 17 & .952 & .921 & .046 \\
\hline
\end{tabular}

Note. Pro $=$ Promotive, Pre $=$ Preventive, Obse $=$ Obsessive

Table 8. Convergent and discriminant validity of self-development sub scale (Study 2)

\begin{tabular}{cccccc}
\hline \multirow{2}{*}{$\begin{array}{c}\text { Self-development } \\
\text { sub scale }\end{array}$} & AVE & C.R & Correlation \\
\cline { 5 - 6 } & & & Promotive & Preventive & Obsessive \\
\hline Promotive & .63 & .83 & $(.82)$ & \\
Preventive & .60 & .82 & $.54^{* * *}$ & $(.78)$ & \\
Obsessive & .80 & .88 & $.39^{* * *}$ & $.45^{* * *}$ & $(.90)$ \\
\hline
\end{tabular}

${ }^{* * * *} p<.001,($ Cronbach's alpha) 
한국심리학회지: 산업 및 조직

Table 9. Mean difference test by gender, grade, and Major (study 2)

\begin{tabular}{|c|c|c|c|c|c|c|c|c|c|}
\hline \multirow[b]{2}{*}{ variable } & \multicolumn{2}{|c|}{ Gender } & \multirow[b]{2}{*}{$t$} & \multicolumn{2}{|c|}{ Grade } & \multirow[b]{2}{*}{$t$} & \multicolumn{2}{|c|}{ Major } & \multirow[b]{2}{*}{$t$} \\
\hline & $\begin{array}{c}\text { Male } \\
(55.8 \%)\end{array}$ & $\begin{array}{l}\text { Female } \\
(44.2 \%)\end{array}$ & & $\begin{array}{l}\text { Lower } \\
(50.5 \%)\end{array}$ & $\begin{array}{c}\text { Upper } \\
(49.5 \%)\end{array}$ & & $\begin{array}{c}\text { Literature } \\
(48.8 \%)\end{array}$ & $\begin{array}{l}\text { Science } \\
(51.2 \%)\end{array}$ & \\
\hline \multicolumn{10}{|l|}{ Self-development } \\
\hline Promotive & 3.59 & 3.55 & .53 & 3.63 & 3.52 & 1.77 & 3.63 & 3.52 & 1.71 \\
\hline Preventive & 3.77 & 3.67 & 1.81 & 3.74 & 3.71 & .41 & 3.73 & 3.72 & .11 \\
\hline Obsessive & 3.22 & 2.99 & $2.87^{* *}$ & 3.18 & 3.06 & 1.43 & 3.13 & 3.10 & .37 \\
\hline Career anxiety & 2.52 & 2.22 & $2.79^{* *}$ & 2.17 & 2.60 & $-4.19^{* * * *}$ & 2.31 & 2.46 & -1.48 \\
\hline Internal prejudice & 3.28 & 2.97 & $3.19^{* *}$ & 3.09 & 3.20 & -1.05 & 3.16 & 3.13 & .23 \\
\hline Career behavior & 3.00 & 2.76 & $3.46^{* * *}$ & 2.84 & 2.95 & -1.49 & 2.82 & 2.96 & $-2.05^{*}$ \\
\hline Career maturity & 3.18 & 3.56 & $-3.74^{* * *}$ & 3.25 & 3.26 & -.19 & 3.31 & 3.21 & $2.11^{*}$ \\
\hline Career decision & 3.19 & 3.43 & $-3.08^{* * *}$ & 3.34 & 3.25 & 1.04 & 3.37 & 3.22 & 1.79 \\
\hline Life satisfaction & 3.36 & 3.43 & -.75 & 3.48 & 3.30 & $2.08^{*}$ & 3.42 & 3.36 & .65 \\
\hline
\end{tabular}

자기계발에서는 통계적 차이가 없었다. 진로 관련 변인에서는 취업불안 $(t=2.79, p<.01)$, 내면적 편견 $(t=3.19, p<.01)$, 진로준비행동 $(t=3.46, p<.001)$ 은 남학생이 여학생에 비해 높은 것으로 나타났으나, 진로성숙도 $(t=-3.74$, $p<.001)$, 진로결정수준 $(t=-3.08, p<.01)$ 에서는 여학생이 남학생보다 높은 것으로 나타났고, 삶의 만족에서는 성별에 따른 차이가 나타 나지 않았다.

학년별 비교에서는 세 가지 자기계발 모두 고학년이 저학년에 비해 다소 높은 평균을 보여주었으나 통계적으로 유의한 차이가 아 니었다. 진로 관련 변인 중 취업불안 $(t=-4.19$, $p<.001)$ 은 고학년이 저학년보다 높았고, 삶의 만족( $t=2.08, p<.05)$ 은 저학년이 고학년보다 높았으며 그 이외에는 학년 별 차이가 나타나 지 않았다.

전공별 비교에서는 세 가지 자기계발 모두 인문사회와 자연이공 계열 간 차이를 보여주
지 않았으며, 진로 관련 변인에서도 자연이공 계열이 진로준비 행동( $t=-2.05, p<.05)$ 을 다소 높게 보여주고, 인문사회 계열이 진로성숙도 $(t=2.11, p<.05)$ 를 다소 높게 보여준 것 이외 에는 전공별 차이가 나타나지 않았다.

\section{중다회귀분석}

자기계발이 취업 및 진로 관련 변인에 미치 는 영향을 확인하기 위해 변인별로 중다회귀 분석을 실시했다. 그 결과를 요약하여 Table 10 에 제시하였다.

먼저 취업불안에 대하여 향상적 자기계발은 취업불안을 낮추었으며 $(\beta=-.26, p<.001)$ (가설 1-1 지지), 강박적 자기계발은 취업불안을 높 였으나 $(\beta=.41, p<.001)$, 예방적 지지는 영향을 미치지 않았다(가설 1-2 부분 지지). 진로성숙 도에 대해서는 향상적 자기계발이 진로성숙도 를 높이고 $(\beta=.16, p<.05)$ (가설 2-1 지지), 강박 
허창구 / 스펙경쟁 사회에서 자기계발 동기와 자기계발 강박이 취업준비생의 심리상태에 미치는 영향

Table 10. Multiple regression for the effect of three self-developments $(\beta)$

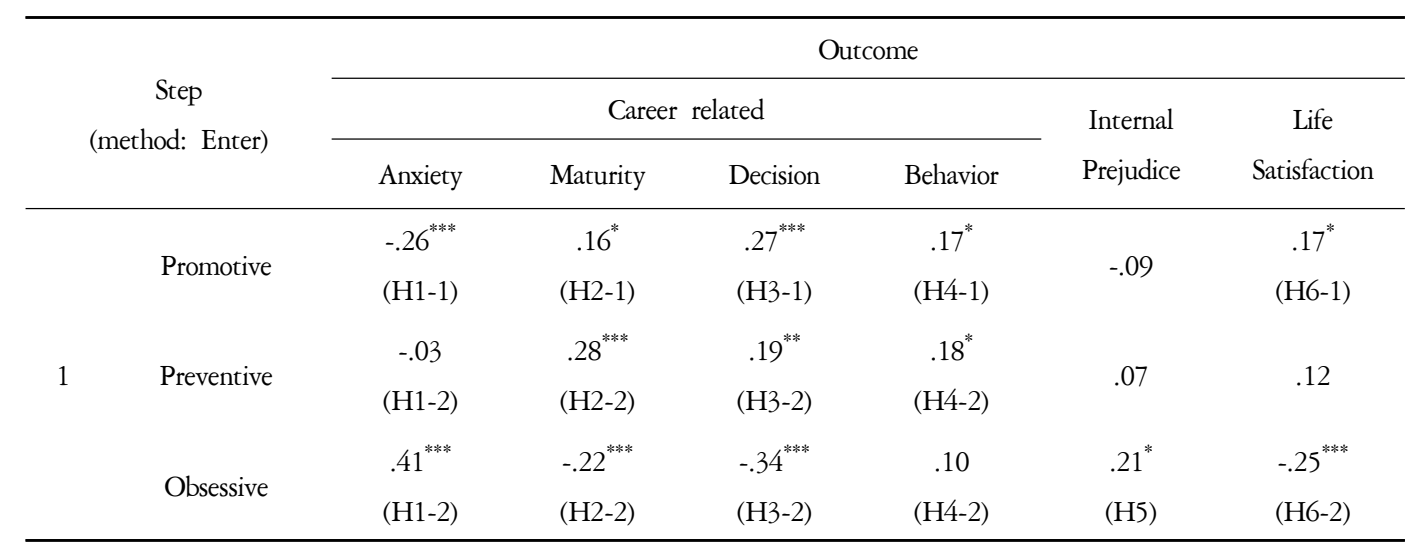

$* p<.05, * * p<.01, * * * p<.001$

적 자기계발은 진로성숙을 낮추는 것으로 나 타났으나 $(\beta=-.22, p<.001)$, 예방적 자기계발 또 한 진로성숙을 높이는 것으로 나타났다 $\beta=.28$, $p<.001)$ (가설 2-2 부분 지지). 진로결정수준에 대해서는 향상적 개발이 진로결정수준을 높이 고 $(\beta=.27, p<.001)$ (가설 3-1 지지), 강박적 자기 계발이 진로결정수준을 낮추는 것으로 나타났 으나 $(\beta=-34, \quad p<.001)$, 예방적 자기계발 또한 진로결정수준을 높이는 것으로 나타났다 $(\beta$ $=.19, p<.01$ )(가설 3-2 부분 지지). 진로준비행 동에 대해서는 향상적 자기계발이 진로준비행 동을 높였으나 $\beta=.17, p<.05)$ (가설 4-1 지지), 예방적 자기계발 또한 진로준비행동을 높이는 것으로 나타났으며 $\beta=.18, p<.05)$, 강박적 자 기계발의 경우 영향을 미치지 않는 것으로 나 타났다(가설 4-2 기각). 사회적 차별에 대한 내 면적 편견에 대해서는 강박적 자기계발이 높 을수록 내면적 편견이 높은 것으로 나타났다 $(\beta=.21, p<.05)$ (가설 5 지지). 삶의 만족의 경 우 향상적 자기계발은 삶의 만족을 높이고 $\beta$ $=.17, p<.05$ )(가설 6-1 지지) 강박적 자기계발 은 삶의 만족을 낮추는 것으로 나타났다 $\beta$
$=-.25, p<.001)$ (가설 6-2 지지).

\section{연구 2 결론}

이상의 결과를 통해 보았을 때, 세 가지 자 기계발(향상적, 예방적, 강박적) 척도의 문항은 연구 1 과 마찬가지로 연구 2 에서도 구성타당 성을 보여주었다.

인구 통계적 측면에서 의미 있는 차이로는 취업불안, 내면적 편견, 준비행동에서는 남학 생이 높았으나 진로성숙과 진로의사결정에서 는 오히려 여학생이 높았다. 이는 취업불안, 내면적 편견이 진로성숙과 진로의사결정에 부 정적인 영향을 미칠 수 있으며, 준비행동을 많이 한다고 해서 높은 진로성숙과 진로의사 결정 수준이 담보되는 것은 아님을 말해준다.

가설의 지지 여부를 통해 연구 2 의 결과를 종합하면 다음과 같다. 첫째, 향상적 자기계발 의 긍정적 영향에 대한 가설(1-1, 2-1, 3-1, 4-1, 6-1)은 모두 지지 되었다. 예측했던 대로 자기 성장과 발전을 위한 향상적 자기계발은 자기 
주도적인 진로준비행동을 통해 진로성숙도와 진로결정수준을 높이며 결과적으로 취업불안 을 낮추고 삶의 만족도를 높이는 긍정적인 영 향을 미치고 있었다.

둘째, 강박적 자기계발의 부정적인 영향에 대한 가설 중에서 진로준비행동(4-2)을 제외한 모든 가설(1-2, 2-2, 3-2, 5, 6-2)이 지지 되었다. 즉, 강박적 자기계발이 높다고 해서 진로준비 행동이 낮아지지는 않았지만, 강박적 자기계 발은 취업불안과 내면적 편견을 높이며 진로 성숙도와 진로결정수준 및 삶의 만족도에 부 정적인 영향을 미치고 있었다.

셋째, 예방적 자기계발의 부정적 영향에 대 한 가설은 모두 기각되었다. 즉, 예방적 자기 계발이 높다고 해서 취업불안이 높게 나타나 지는 않았으며, 가설과 반대로 예방적 자기계 발이 높은 수록 진로성숙도, 진로경정수준, 진 로준비행동이 높은 것으로 나타났다. 이러한 결과의 의미를 찾자면, 비록 사후해석이긴 하 지만, 예방적 자기계발동기가 높은 학생들도 자기계발을 통해 진로준비행동을 많이 하게 되고 그 과정에서 진로결정수준이 높아질 수 있다고 해석할 수 있으며 이는 가설수립 과정 에서 고려하지 못했던 부분이었다. 하지만, 향 상적 자기계발 동기뿐 아니라 예방적 자기계 발 동기가 높은 학생들도 높은 진로성숙도를 보여준다는 결과는 일반적인 수준에서 수용하 기 어려운 부분이 있었다. 이러한 결과의 한 가지 원인을 진로성숙도 문항(예, "자신의 직 업은 자기 스스로 결정해야 한다")에 대한 사 회적 바람직성 반응에서 찾아볼 수 있는데, 자기계발 동기가 높은 학생들은 자신의 진로 선택에 대해서도 높은 관심이 있을 것이며 그 러한 상황에서 어떻게 자기의 진로를 선택했 는지를 묻는 질문이 아닌 어떻게 선택해야 한
다고 생각하는가를 묻는 질문 형식이 실제 자 신의 선택과는 다른 바람직한 응답을 일으켰 을 가능성이 있다.

마지막으로 경쟁적 자기계발이 사회적 차별 에 대한 개인의 내면적 편견을 키운다는 $\mathrm{Oh}(2011)$ 의 사회학적 관점의 주장은 본 연구 에서 강박적 자기계발만이 내면적 편견에 정 적 영향을 미치는 결과를 보여줌으로써 심리 학적 측면에서도 확인되었다고 할 수 있다.

\section{종합 논의}

본 연구는 자기계발 동기와 강박적 자기계 발을 측정할 수 있는 도구를 개발하고, 이를 바탕으로 자기계발 동기와 자기계발 강박이 자기계발 당사자에게 미치는 심리적 영향을 확인하였다. 이를 통해 가장 바람직한 자기계 발 동기 경향성은 향상적 자기계발이며, 대학 생들이 가장 높은 점수를 보여준 예방적 자기 계발의 경우 비록 수동적인 자기계발 동기이 긴 하지만 진로준비행동이나 진로결정수준, 진로성숙도에 긍정적인 영향을 미치고 있었다. 한편 불안에 근거한 강박적 자기계발의 경우 취업 및 진로와 관련된 모든 심리적 변인에서 부정적인 영향을 미치는 것을 확인하였다.

본 연구가 지니는 학문적 의의 및 기대효과 는 다음과 같다. 첫째, 사회를 구성하는 구성 원의 심리적 현상을 통해 사회현상의 원인과 결과를 보다 세부적으로 이해하는 접근법을 시도하였다. 이를 통해 사회현상으로 다뤄져 온 스펙경쟁에 대한 심리학적 접근을 시도함 으로써 융합학문적 연구결과를 제시하였다. 둘째, 스펙경쟁과 관련된 심리적 현상을 자기 계발 동기로 구분하고, 자기계발의 강박적 수 
준을 측정하는 도구를 제공하였다. 이는 스펙 경쟁을 불안수준으로만 바라보던 기존 일차원 적 해석의 스펙트럼을 다각적으로 확대시킬 수 있을 것으로 기대한다. 셋째, 세 가지 자기 계발(향상적, 예방적, 강박적)과 다양한 진로 관련 변인 간의 관련성을 통해 자기계발 동기 의 방향에 따른 차별적 영향력을 확인하였다. 그로 인해 건전한 자기계발 동기를 부정적 자 기계발 즉, 불안으로부터 기인한 강박적 자기 계발과 개념적으로 구분하여 다룰 수 있는 기 초를 제공하였다는 데 의미가 있다. 넷째, 취 업준비생의 세 가지 자기계발(향상적, 예방적, 강박적)을 진단함으로써 보다 건전한 자기계 발의 방향을 제시할 수 있을 것으로 기대한다. 다시 말해, 취업 및 진로지도 장면에서 자기 계발 동기와 강박수준에 따라 향상적 자기계 발 동기를 강화하거나 강박적 자기계발을 유 발하는 비합리적 신념과 왜곡된 고정관념을 수정함으로써 자기계발에 대한 바람직한 도식 을 재구성하도록 지도할 수 있을 것이다.

본 연구가 지닌 제한점 및 향후 연구를 위 한 제언은 다음과 같다. 첫째, 본 연구의 결과 는 세 가지 자기계발이 취업 및 진로 관련 변 인에 미친 직접적인 영향을 살펴보는 데 그치 고 있어, 자기계발 동기의 발생 과정이나 영 향과정을 보여주지 못하는 한계가 있다. 따라 서 향후에는 세 가지 자기계발의 차별적 원인 에 관한 연구나 이들이 취업 및 진로 관련 변 인에 영향을 미치는 과정에서의 매개변인 및 조절변인의 가능성을 확인하는 연구가 이어질 필요가 있다. 둘째, 세 가지 자기계발이 정적 상관관계를 보여줌으로써 상호배타적 개념이 아닌 것을 알 수 있었다. 따라서 자기계발 동 기와 자기계발 강박수준의 상호작용이 취업준 비생의 취업 및 진로 관련 심리상태에 미치는
영향을 살펴볼 필요가 있을 것으로 보인다. 마지막으로 세 가지 자기계발의 개념적 틀을 구성하기 위해 기존의 이론과 문항에 근거하 는 과정에서 자기계발의 중요한 속성이 결여 되었을 가능성이 있다. 따라서 향후 연구에서 는 자기계발과 관련된 보다 다양한 심리적 속 성의 고려가 추가로 이루어질 필요가 있을 것 이다.

\section{참고문헌}

Ahn, S. J. (2016, August 22). Monthly self-development expenses 175,000 won for college students and 229,000 won for office workers. Job Korea. https://tinyurl.com/ql3smoz

Aziz, S., Uhrich, B., Wuensch, K. L., \& Swords, B. (2013). The workaholism analysis questionnaire: Emphasizing work-life imbalance and addiction in the measurement of workaholism. Journal of Behavioral and Applied Management, 14(2), 71-86.

https://tinyurl.com/ t57n3sf

Ban, J. S. (2014). A study on the causal relationship between job-seeking and performance in organizations. [Unpublished master's dissertation]. Korea University. https://tinyurl. com/vxay9k7

Bandura, A. (1986). Social foundations of thought and action. Prentice-Hall, Englewood Cliffs, NJ. https://doi.org/10.4135/9781446221129.n6

Bauman, Z. (2013). Liquid times: Living in an age of uncertainty. John Wiley \& Sons.

Button, S. B., Mathieu, J. E., \& Zajac, D. M. (1996). Goal orientation in organizational 
research: A conceptual and empirical foundation. Organizational Behavior and Human Decision Processes, 67(1), 26-48. https://doi.org/ 10.1006/obhd.1996.0063

Carver, C. S., \& Scheier, M. F. (1990). Origins and functions of positive and negative affect: A control-process view. Psychological Review, 97(1), 19-35.

https://doi.org/10.1037/0033-295X.97.1.19

Chae, C. G. (2012). Profile building competition among 4-year university students. KRIVET Issue Brief, 16, 1-4. https://tinyurl.com/tnyoeyz

Chang, S. M. (1991). A Study on the Standardization of Career Maturity Inventory (RR91-05). Korean Educational Development Institute.

Cho, G. P. (2008). A study of development and validation of the job-seeking anxiety test for university students. Journal of Education, 46(2), 53-75.

Chung, M. J. (2014). The study of the effects of inferiority, employment anxiety and satisfaction in major on the employment preparation behavior of the undergraduates majoring in airline service. Journal of Tourism and Leisure Research, 26(7), 335-354.

Crites, J. O. (1978). Manual for the career maturity inventory for adults. Monterey, CA: CTB/ McGraw-HiU.

Fellner, B., Holler, M., Kirchler, E., \& Schabmann, A. (2007). Regulatory focus scale (RFS): Development of a scale to record dispositional regulatory focus. Swiss Journal of Psychology, 66(2), 109-116.

https://doi.org/10.1024/1421- 0185.66.2.109
Fuqua, D. R., Newman, J. L., \& Seaworth, T. B. (1988). Relation of state and trait anxiety to different components of career indecision. Journal of Counseling Psychology, 35(2), $\begin{array}{llllll}5 & 4 & - & 1 & 5 & 8\end{array}$. https://doi.org/10.1037/0022-0167.35.2.154

Gorman, C. A., Meriac, J. P., Overstreet, B. L., Apodaca, S., McIntyre, A. L., Park, P., \& Godbey, J. N. (2012). A meta-analysis of the regulatory focus nomological network: Work-related antecedents and consequences. Journal of Vocational Behavior, $80(1)$ $\begin{array}{lllllll}1 & 6 & 0 & - & 1 & 7 & 2\end{array}$. https://doi.org/10.1016/j.jvb.2011.07.005

Han, S. M. (1997). Social network and life satisfaction of the people with disability. [Unpublished master's dissertation]. Catholic University. http://www.riss.kr/link?id=T7897 470

Higgins, E. T. (1998). Promotion and prevention: Regulatory focus as a motivational principle. Advances in Experimental Social Psychology, 30, $1-46$.

https://doi.org/10.1016/S0065-2601(08) 60381-0

Higgins, E. T., Shah, J., \& Friedman, R. (1997). Emotional responses to goal attainment: strength of regulatory focus as moderator. Journal of Personality and Social Psychology, 72(3), 515-525.

https://doi.org/10.1037/0022- 3514.72.3.515

Iem, Y. S. (2018). Anxiety experiences in the youth through the gaze of university students. Journal of Democracy and Human Rights, 18(1), 105-152.

Jang, S. Y. (2013). A study on the 'spec-building' 
experiences of large company employees who graduated from 4-year-course universities in the capital area. [Unpublished master's dissertation]. Seoul National University. https://tinyurl.com/u76ugyk

Jo, H. I., \& Oh, H. S. (2011). The effects of regulatory focus and cognitive expectancy on career exploration activities. Korean Journal of Youth Studies, 18(2), 123-143.

Jo, M. J. (2010). The effects of career maturity of college students on job-seeking anxiety and stress. The Study of Job \& Employment Service, 5(2), 47-60. https://tinyurl.com/sy8t3y8 Jung, H. M. (2016). Study on college students' perception on self-development. The Journal of Learner-Centered Curriculum and Instruction, 164), 575-596.

Jung, U. S., \& No, A. Y. (2001). Study of the relations among job-seeking stress, depression, self-esteem and physical health of university student. Student Life Research of Chonnam National University, 33(12), 85-101.

Kang, M. Y. (2012). Moderation Effects of Career Decision-making self-efficacy, Job seeking activity, Spec 5 activity, on the relation of Job Preparing Stress and the Adjustment to College of University Students. [Unpublished master's dissertation]. Chonnam National University.

https://tinyurl. com/renrc72

Kim, B. W., \& Kim, K. H. (1997). Career Decision Level and Career Preparation Behavior of the College Students. The Korean Journal of Counseling and Psychotherapy, 91), 311-333.
Kim, B. W., Jung, C. Y., \& Kim, B. S. (2006). School Career Counseling (2nd ed.). Seoul: Hakjisa.

Kim, H. Y., \& Lee, D. G. (2009). The relation between employees' motivation for self-development and psychological well-being. Korean Journal of Industrial and Organizational Psychology, 22(2), 261-293. https://doi.org/ 10.24230/ksiop.22.2.200905.261

Kim, J. W., \& Min, B. M. (1998). Intolerance of uncertainty and problem orientation in worry. Journal of the Korean Psychological Association Annual Conference, 1998(1), 83-92.

Kim, K. H. (2002). The psychological perspectives of addictive behaviors. The Korean Journal of Health Psychology, 7(2), 159-179.

Kim, K. H. (2007). A way to overcome addiction the modern dungeon. The Korean Journal of Health Psychology, 12(4), 677-693. https:// doi.org/10.17315/kjhp.2007.12.4.001

Kim, K. S., Kim, N. J., \& Oh, S. I. (2017). Self-development and the quality of life among university students in Korea. The Journal of Social Science, 24(2), 259-294.

Kim, S. H. (2012). 'Qualification-Building' of college students: Human capital investment or symbolic capital acquisition. The Korean Sociological Association, 97-108.

Kim, Y. H., Yoo, S. K., \& Lim, J. S. (2011). The mediating effects of attitudes toward multiple role planning and self-efficacy in the relationship between career orientation and life-satisfaction among Korean female college students. Studies on Korean Youth, 22(4), 
161-185.

Ko, G. P., \& Sim, M. Y. (2014). The structural relation of self-efficacy, job stress, career maturity and career preparation behavior of college students. The Journal of Career Education Research, 27(1), 19-38.

Korea Labor \& Income Panel Study (2014). https://tinyurl.com/udkh66z

Lee, B. H., Du, X., Rhee, E. J., Jang, S. H., Jung, S. H., \& Lee, S. M. (2013) The mediation dffect of career decision-making styles in the relationship between college students' trait anxiety and career indecision. Korean Journal of Counseling, 14(2), $\begin{array}{lllllllll}1 & 3 & 8 & 3 & - & 1 & 4 & 0 & 0\end{array}$. http://doi.org/10.15703/kjc.14.2.201304.1383

Lee, J. I. (2014). Resume and labor market performance of job applicants. [Unpublished master's dissertation]. Hanyang University. https://tinyurl.com/slnzsea

Lee, J. K., \& Kim, D. I. (2004). Employment preparation behavior of the college students: Focused on the psychological differences.

Korean Counseling Association, 5(4), 993-1016. https:/tinyurl.com/vaszymx

Lee, J. M. (2008). Educational expenditure and rates of return to higher education (RR2008-15). Korean Educational Development Institute.

Lee, M. S. (2003). Analysis of relationship among career self-efficacy, career barriers perception, and career preparation behavior of college students. [Unpublished master's dissertation]. Jeonju University. https://tinyurl.com/t7ekdbg

Lee, Y. K., \& Kang, K. H. (2011). The analysis about employment stress and career decision efficacy of undergraduates-In focus of engineering and social science colleges. Journal of Engineering Education Research, 14(2), 60-67. http://doi.org/10.18108/jeer.2011.14.2.60

Lim, Y. J. (2012). Efficacy of positive psychotherapy on college students with major depressive disorder. Korean Journal of Clinical Psychology, 31(3), 679-692.

http://doi.org/ 10.15842/kjcp.2012.31.3.003

Marlatt, G. A., Baer, J. S., Donovan, D. M., \& Kivlahan, D. R. (1988). Addictive behaviors: Etiology and treatment. Annual Review of Psychology, 39(1), 223-252.

https://doi.org/10.1146/ annurev.ps.39.020188.001255

McGee, M. (2005). Self-help, inc.: Makeover culture in American life. Oxford University $\begin{array}{lllll}\mathrm{P} & \mathrm{r} & \mathrm{e} & \mathrm{s} & \mathrm{s}\end{array}$ https://doi.org/10.1093/acprof:oso/97801951712 42.001 .0001

Park, Y. (2004). New words [신어]. National Institute of Korean Language. https://lod.nl.go. kr/page/CNTS-00061102626

Neubert, M. J., Kacmar, K. M., Carlson, D. S., Chonko, L. B., \& Roberts, J. A. (2008). Regulatory focus as a mediator of the influence of initiating structure and servant leadership on employee behavior. Journal of Applied Psychology, 93(6), 1220-1233. https:// doi.org/10.1037/a0012695

Oh, C. H. (2011). Age of anxiety, survival strategies for university students in their twenties. [Unpublished doctoral dissertation]. Sogang University. https://tinyurl.com/uah5qsq 
Oh, E. J. (2014). Effect of trait anxiety on college students' career preparation behavior: The mediating effects of career decision making self-efficacy. The Journal of Career Education Research, 27(2), 85-107.

Oh, H. Y. (2013). Employment SPECS of envy workplace and policy project of college graduates. The HRD Review, 10(2), 78-101. https://tinyurl.com/r67maoe

Park, S. M. (2013). The influence of college students' career maturity on their job-seeking stress: the mediating effect of self-efficacy. [Unpublished master's dissertation]. Kyungsung University. https://tinyurl.com/w2r6t86

Reed, G. F. (1985). Obssessional experience and compulsive behaviour: A cognitive-structural approach. Orlando, FL: Academic Press.

Roseman, I. J., Spindel, M. S., \& Jose, P. E. (1990). Appraisals of emotion-eliciting events: Testing a theory of discrete emotions. Journal of Personality and Social Psychology, 59(5), 899-915.

https://doi.org/10.1037/0022-3514.59.5.899

Seligman, M. E. (2004). Authentic happiness: Using the new positive psychology to realize your potential for lasting fulfillment. Simon and Schuster.

Shin, J. M., Lea, E. K., \& Yang, N. M. (2015). The effects of career calling on career decision-making self-efficacy and life-satisfaction in college students. Journal of Social Science, 54(1), 169-194.

https://doi.org/10.22418/jss. 2015.06.54.1.169

Shin, K. Y., \& Moon, S. Y. (2014). Social class, gender and shadow education in South Korea.
Korean Journal of Labor Studies, 201),

$\begin{array}{lllll}3 & 1 & - & 6 & 4\end{array}$

http://doi.org/10.17005/kals.2014.20.1.31

Shin, M. S., \& Seol, S. H. (2007). Cognitive behavior therapy for obsessive-compulsive disorder. Cognitive Behavior Therapy in Korea, $71), 17-40$.

So, Y. J., \& Park, J. S. (2016). The influence of university students' job-seeking stress on career maturity in university adjustment: Focusing on the mediating effect of job-seeking anxiety. Journal of Employment and Career, Q4), 23-44.

http://doi.org/10.35273/ jec.2016.6.4.002

Super, D. E. (1953). A theory of vocational development. American Psychologist, 8(5), 185- 190. https://doi.org/10.1037/h0056046

Turner, M. J., Allen, M. S., Slater, M. J., Barker, J. B., Woodcock, C., Harwood, C. G., \& McFayden, K. (2016). The development and initial validation of the irrational performance beliefs inventory (iPBI). European Journal of Psychological Assessment. 34(3), 174-180. https://doi.org/10.1027/1015-5759/a000314

Wilhelm, S., \& Steketee, G. S. (2006). Cognitive therapy for obsessive compulsive disorder: $A$ guide for professionals (Shin, M. S., Seol, S. H., \& Kwon, J. S., Trans.). Sigmapress. https://tinyurl.com/tc7lzym

Yang, O. G. (1994). Development of a scale to measure life satisfaction. Korean Journal of Social Welfare, 24, 157-198.

Yang, Y., \& Kim, E. S. (2008). The effect of chronic/situational regulatory focus and task performance feedback on consumer affect. The 
한국심리학회지: 산업 및 조직

Korea Journal of Consumer and Advertising

Psychology. 93), 407-433.

http://doi.org/ 10.21074/kjlcap.2008.9.3.407

Yoon, J. Y., Choi, S. H., \& Hur, T. K. (2013)

The development and validation of the leisure obsession scale. Korean Journal of Culture and Social Issues, 19(2), 235-257.

Yun, S. M., \& Kang, J. R. (2013). The effects of a strengths-based career counseling program 투고일자 : 2020. 02. 07 on elementary school children's career maturity and achievement motivation. Journal of 수정일자 : 2020. 02. 21 게재확정 : 2020. 02. 20 Learner-Centered Curriculum and Instruction, 13(1), 103-123. 


\title{
The Influences of Self-Improvement Motivation and Obsessive Self-Improvement on Psychological State of Undergraduate Student
}

\author{
Heo, Chang-Goo \\ Daegu Catholic University
}

\begin{abstract}
The purpose of this study was to understand the phenomenon of 'SPEC pursuit' in the psychological aspect. In study 1, 'SPEC pursuit' was redefined as 'self-development'; and self-development motivation (promoting, preventive) scale and obsessive self-development scale were developed to measure it. These three self-development scales (promoting, prophylactic, and obsessive) showed logically valid correlations with the regulatory focuse (promoting, preventing), goal orientation (learning, performance), worry, and obsessive-compulsive scale. Study 2 was conducted to confirm the effect of three self-development on psychological variables related to career and employment (job anxiety, career maturity, career decision-making, career preparation behavior, internal prejudice, life satisfaction). As a result, the positive effect of the promotional self-development and the negative effect of the obsessive self-development were supported. On the other hand, the negative effect of preventive self-development, which was assumed to have a negative effect, was not observed. It is expected that the tools and results developed in this study will be used for desirable self-development guidance and counseling for students.
\end{abstract}

Key words : SPEC, self-improvement motivation, obsessive self-improvement, regulatory focus 